\title{
AVALIAÇÃO DO AMACIAMENTO ESTÁTICO A QUENTE E A MORNO DE UM AÇO SILICIOSO
}

\section{Resumo}

Realizaram-se ensaios de compressão a quente com dupla deformação num aço ultrabaixo carbono, ligado ao silício e alumínio. Variou-se a taxa de deformação $\left(1 \mathrm{~s}^{-1} ; 10 \mathrm{~s}^{-1}\right.$ e $\left.30 \mathrm{~s}^{-1}\right)$, a temperatura $\left(1.050^{\circ} \mathrm{C}\right.$ - fase austenítica; $950^{\circ} \mathrm{C}$ - região intercrítica e $850^{\circ} \mathrm{C}$ - fase ferrítica) e o tempo entre passes $(0,5 \mathrm{~s} ;$ I s; $5 \mathrm{~s}$ e $50 \mathrm{~s})$, mantendo-se a deformação verdadeira dos dois passes igual a 0,2 . As temperaturas empregadas cobriram a faixa aplicada na laminação industrial de acabamento do aço. A avaliação das características de amaciamento estático foi feita a partir das curvas de fluxo. Verificaram-se características similares de amaciamento nas três temperaturas ensaiadas, com a fração amaciada crescendo com o tempo entre passes e com a taxa de deformação. Informações obtidas das curvas de amaciamento e evidências microestruturais indicam que, nas duas maiores temperaturas (fase austenítica e parte superior da região intercrítica), o processo de restauração é governado por recristalização descontínua, com formação e crescimento de subgrãos. Já na menor temperatura (fase ferrítica) a restauração é principalmente ditada por movimentação de contornos induzida por deformação (processo SIBM) e recuperação.

Palavras-chave: Aço silicioso; Ensaio de compressão; Recristalização; Laminação a morno.

\section{EVALUATION OF STATIC SOFTENING DURING HOT AND WARM DEFORMATION OF A SILICON STEEL}

\begin{abstract}
Double hit compression tests were performed on an ultra low carbon Si-Al alloyed steel. The true strain in both deformation steps was kept constant (0.2), while varying the strain rate $\left(1 \mathrm{~s}^{-1}, 10 \mathrm{~s}^{-1}\right.$ and $\left.30 \mathrm{~s}^{-1}\right)$, the temperature $\left(\mathrm{I}, 050^{\circ} \mathrm{C}\right.$-austenite phase, $950^{\circ} \mathrm{C}$-intercritical region and $850^{\circ} \mathrm{C}$-ferritic phase) and the interpass time $(0.5 ; \mathrm{I} ; 5$ and $50 \mathrm{~s})$. The temperatures used are within the industrial range applied in the finishing rolling for this steel. The analysis of the flow curves obtained allowed the evaluation of the static softening characteristics of the steel. It was shown that the steel has a similar softening condition between passes at the three temperatures studied, with the softening fraction increasing with the increasing time and strain rate. The characteristics of the softening curves and microstructural features indicate that at the two higher temperatures (austenite phase and upper part of the intercritical region) the softening process is governed by recrystallization, with the nucleation and growth of subgrains. At the lower temperature, however, the softening is mainly due to strain induced boundary movement (SIBM) and recovery.

Key words: Silicon steel; Compression test; Recrystallization; Ferritic rolling.

\section{INTRODUÇÃO}

Os aços "elétricos" de grão-não-orientado (GNO) são aplicados principalmente nos núcleos de dispositivos eletromagnéticos rotativos, como geradores e motores. Existe, atualmente, a tendência da fabricação destes materiais na condição de ultrabaixo carbono e com moderadas adições de silício e alumínio. ${ }^{(1,2)}$

Devido ao baixo teor de carbono, elemento austenitizante, e à adição de $\mathrm{Si}$ e $\mathrm{Al}$, elementos ferritizantes, estes aços são comumente acabados sob a condição de laminação a morno, ou seja, os últimos passes da laminação a "quente" de acabamento ocorrem na fase ferrítica.

Deve ser chamada a atenção para o fato dos aços ultrabaixo carbono comuns serem processados a quente nas usinas siderúrgicas normalmente na fase austenítica. Desta forma, pouco conhecimento se tem do comportamento na laminação dos aços elétricos modernos. Por isto, neste trabalho são avaliadas as características de amacimento entre passes na faixa de temperaturas na qual um aço ultrabaixo carbono, ao silício e alumínio, é processado industrialmente na laminação de acabamento.
\end{abstract}

'Membro da ABM; Engenheiro Metalurgista, Dr., Superintendência de Marketing da Usiminas; Belo Horizonte, MG. BR 38I/SN; kmarra@usiminas.com.br

${ }^{2}$ Membro da ABM; Engenheiro Mecânico, Dr. Ing., Superintendência do Centro de Pesquisa e Desenvolvimento da Usiminas; Ipatinga, MG. BR 38I/ SN; tmelo@ usiminas.com.br 


\section{PROCEDIMENTO EXPERIMENTAL}

Foi utilizado um aço ultrabaixo carbono e com adições de silício e de alumínio. Industrialmente, na etapa de desbaste da laminação a quente, faz-se uma redução da espessura de placa para cerca de $26 \mathrm{~mm}$. Numa segunda etapa, dita acabamento, o esboço tem sua espessura diminuída para $2,5 \mathrm{~mm}$.

A etapa de desbaste ocorre em dois laminadores $4 \mathrm{HI}$, ambos reversíveis. Já a laminação de acabamento dá-se em um trem de laminação com seis cadeiras.

As temperaturas de transformação deste aço, determinadas via ensaio dilatométrico, são $960^{\circ} \mathrm{C}$ e $900^{\circ} \mathrm{C}$ (início e final da transformação gama/alfa). Com isto pode ser inferido que o início da laminação de acabamento ocorre na fase austenítica; nas cadeiras intermediárias, a redução de espessura dá-se na região intercrítica, e a laminação a quente é finalizada na fase ferrítica.

Para a consecução deste trabalho foi obtida uma amostra do aço na entrada do trem de laminação, após a laminação de desbaste. A amostra referiu-se ao topo do esboço. Após corte da ponta do esboço, a amostra foi resfriada ao ar.

As características de amaciamento estático entre passes foram avaliadas pelo método da dupla deformação. Este método consiste em se aplicar, através de ensaios mecânicos de deformação a quente, dois passes sucessivos, normalmente com a mesma quantidade de deformação, geralmente baixa, inferior a 0,3 . $^{(3-5)} \mathrm{Com}$ isto, a restauração estática é avaliada em função do intervalo de tempo entre os dois passes.

Por este método, o grau de amaciamento " $X$ " é calculado pela seguinte expressão:

$$
\mathrm{X}=\frac{\sigma_{\mathrm{m}}-\sigma_{\mathrm{r}}}{\sigma_{\mathrm{m}}-\sigma_{\mathrm{o}}} \cdot 100 \%
$$

em que $\sigma_{m}=$ tensão de fluxo imediatamente antes do descarregamento do $1^{\circ}$ passe; $\sigma_{\circ}=$ tensão de fluxo de escoamento no carregamento ( ${ }^{\circ}$ passe); e $\sigma_{r}=$ tensão de fluxo de escoamento no recarregamento ( $2^{\circ}$ passe).

Como as tensões de fluxo de escoamento $\left(\sigma_{\circ}\right.$ e $\left.\sigma_{r}\right)$ são definidas de modo convencional, para um desvio (off set) de deformação elástica de $0,2 \%$ o método citado é comumente denominado de dupla deformação off set.

Foi usado o ensaio de compressão cilíndrica para a determinação do parâmetro $X$, com os corpos-de-prova cilíndricos sendo confeccionados com o eixo paralelo à direção de laminação, com diâmetro de $10 \mathrm{~mm}$ e altura de $15 \mathrm{~mm}$. Empregou-se um simulador termomecânico Gleeble para a realização dos ensaios de compressão.

Foram aplicadas duas deformações sucessivas por compressão $(0,2)$, com quatro diferentes valores de tempo entre passes $(0,5 \mathrm{~s}$; I s; 5 s e $50 \mathrm{~s}$ ) e sob três taxas de deformação $\left(1 \mathrm{~s}^{-1} ; 10 \mathrm{~s}^{-1}\right.$ e $\left.30 \mathrm{~s}^{-1}\right)$.

As temperaturas de ensaio foram $1.050^{\circ} \mathrm{C}, 950^{\circ} \mathrm{C}, 850^{\circ} \mathrm{C}$ de forma a avaliar o material na região austenítica, intercrítica (parte superior, com maior fração de austenita) e ferrítica. A Figura I mostra esquematicamente o ciclo termomecânico aplicado no ensaio de dupla deformação.

\section{RESULTADOS E DISCUSSÃO}

A Figura 2 apresenta os resultados obtidos. Pode ser visualizado que, nas temperaturas de $950^{\circ} \mathrm{C}$ e $1.050^{\circ} \mathrm{C}$, as curvas apresentam um formato sigmoidal, de acordo com padrão de Avrami, ${ }^{(6-8)}$ característico de processos restaurativos que envolvem nucleação e crescimento de grãos. Nota-se, no entanto, que na temperatura de $850^{\circ} \mathrm{C}$, portanto na região ferrítica, o formato sigmoidal é menos evidente.

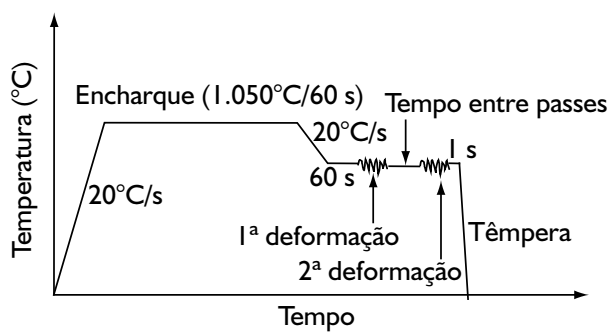

Figura I. Ciclo termomecânico para a aplicação da dupla deformação.
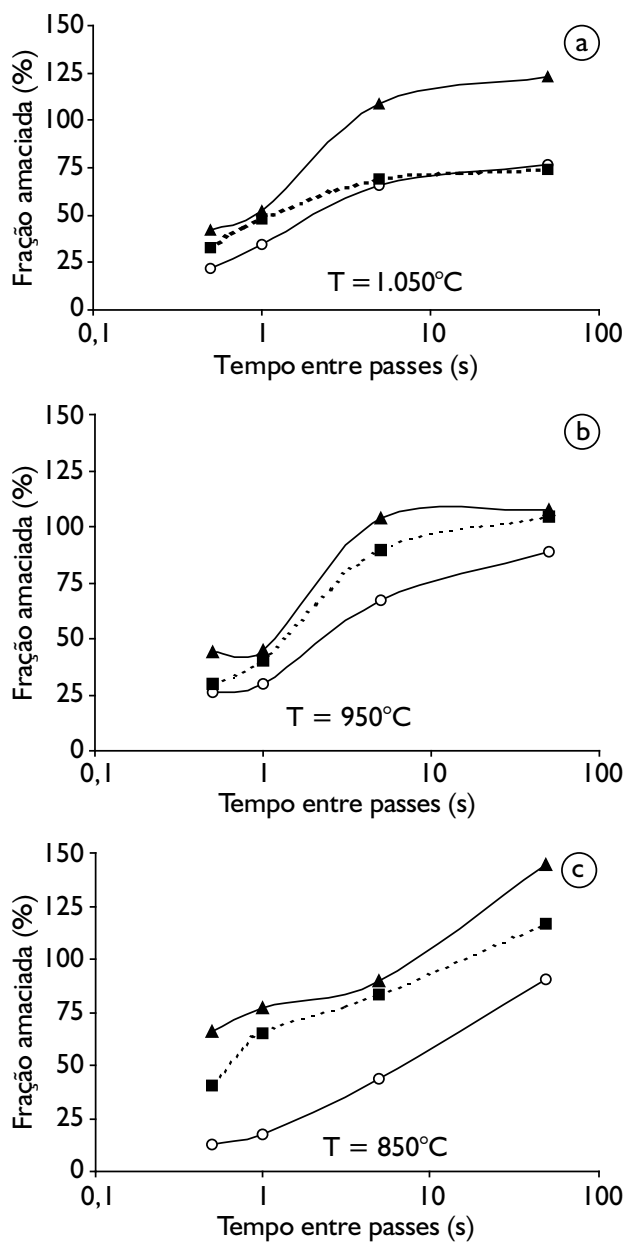

$\multimap$ Taxa $=1 \mathrm{~s}^{-1}--\mathbf{m}--$ Taxa $=10 \mathrm{~s}^{-1} \multimap$ Taxa $=30 \mathrm{~s}^{-1}$

Figura 2. Evolução da fração de amaciamento com o tempo entre passes nas temperaturas de a) $1.050^{\circ} \mathrm{C}$; b) $950^{\circ} \mathrm{C}$; e c) $850^{\circ} \mathrm{C}$. 
Há indícios na Figura 2 de que, nos três patamares de temperaturas empregados, o tempo de incubação para o início do amaciamento foi muito pequeno, ou seja, a restauração microestrutural foi disparada muito rapidamente após a deformação a quente.

Obviamente, o aumento do tempo entre passes contribuiu para uma maior restauração da matriz metálica.

Nota-se, também, que o incremento da taxa de deformação facilitou a ocorrência da recristalização. Isto pode ser justificado pelo aumento da quantidade de sítios para a nucleação heterogênea de novos grãos com o aumento da taxa. Estes sítios são regiões com alta densidade de deslocações, tais como bandas de deformação, fronteiras de células de deformação, vizinhanças de partículas de segunda fase e contornos de grão. Especialmente na maior taxa, $30 \mathrm{~s}^{-1}$, aparecem valores de fração de recristalização superiores a $100 \%$, o que pode indicar, em princípio, uma impossibilidade. No entanto, isto ocorreu certamente em função de uma completa restauração seguida de crescimento de grãos, o que torna o material mais macio em relação a sua situação inicial.

Se forem tomados os tempos para se ter a metade do material amaciado $\left(t_{50}\right)$, ou seja, para $X=50 \%$, numa taxa de $10 \mathrm{~s}^{-1}$, conforme apresenta a Figura 3, pode ser observado que, quando se passa de $1.050^{\circ} \mathrm{C}$ para $950^{\circ} \mathrm{C}$, há um pequeno aumento do parâmetro $t_{50}$. Isto significa que ao deslocar do campo austenítico para a entrada da região bifásica há uma discreta desaceleração no processo de restauração. Isto pode ser justificado pela redução da temperatura, já que a recristalização é um processo termicamente ativado. A matriz metálica, nas duas situações $\left(1.050^{\circ} \mathrm{C}\right.$ e $\left.950^{\circ} \mathrm{C}\right)$ pode ser considerada praticamente austenítica.

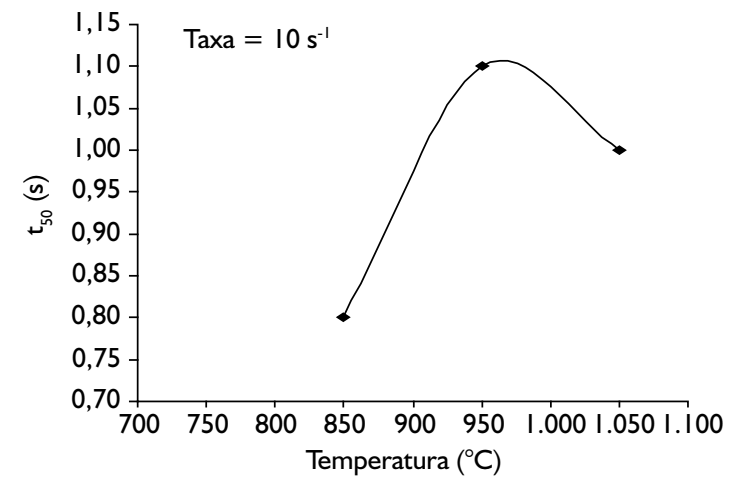

Figura 3. Variação do tempo para $50 \%$ de amaciamento com a temperatura de ensaio.

De outra maneira, de $950^{\circ} \mathrm{C}$ para $850^{\circ} \mathrm{C}$ passou-se de uma microestrutura predominantemente austenítica para uma microestrutura totalmente ferrítica. Pode ser visto na Figura 3 que, embora fosse esperado um atraso na restauração, há uma agilização do amaciamento. Isto deve estar ligado à ativação do mecanismo da recristalização SIBM (movimentação de contornos induzida por deformação), que é operante a altas temperaturas na região ferrítica e que se processa de maneira rápida. ${ }^{(7,9)}$ Aliás, o formato não exatamente sigmoidal das curvas de recristalização observado na Figura 2c sugere que a restauração a $850^{\circ} \mathrm{C}$ deve ser mesmo processada prepoderantemente por SIBM, coadjuvada por recuperação, também bastante operativa na ferrita (material com alta energia de falha de empilhamento).
Adicionalmente foi realizada uma avaliação microestrutural após deformação em ensaio de compressão, também no simulador Gleeble. $O$ ensaio constou de um só passe (deformação verdadeira de 0,2 e taxa $\left.1 \mathrm{~s}^{-1}\right)$, a $850^{\circ} \mathrm{C}, 950^{\circ} \mathrm{C}$ e $1.000^{\circ} \mathrm{C}$, sendo as amostras resfriadas sob jato d'água após $0,5 \mathrm{~s}$ da deformação. Com isto, houve uma restauração parcial. Observações em microscópio óptico mostram indícios de recristalização por SIBM na amostra processada a $850^{\circ} \mathrm{C}$ (contornos de grãos rendilhados e grandes) e recristalização por formação e crescimento de subgrãos nas amostras trabalhadas a $950^{\circ} \mathrm{C}$ e $1.000^{\circ} \mathrm{C}$ (grãos finos e mais definidos dentro de outros ou nos contornos de outros), conforme indica a Figura 4.
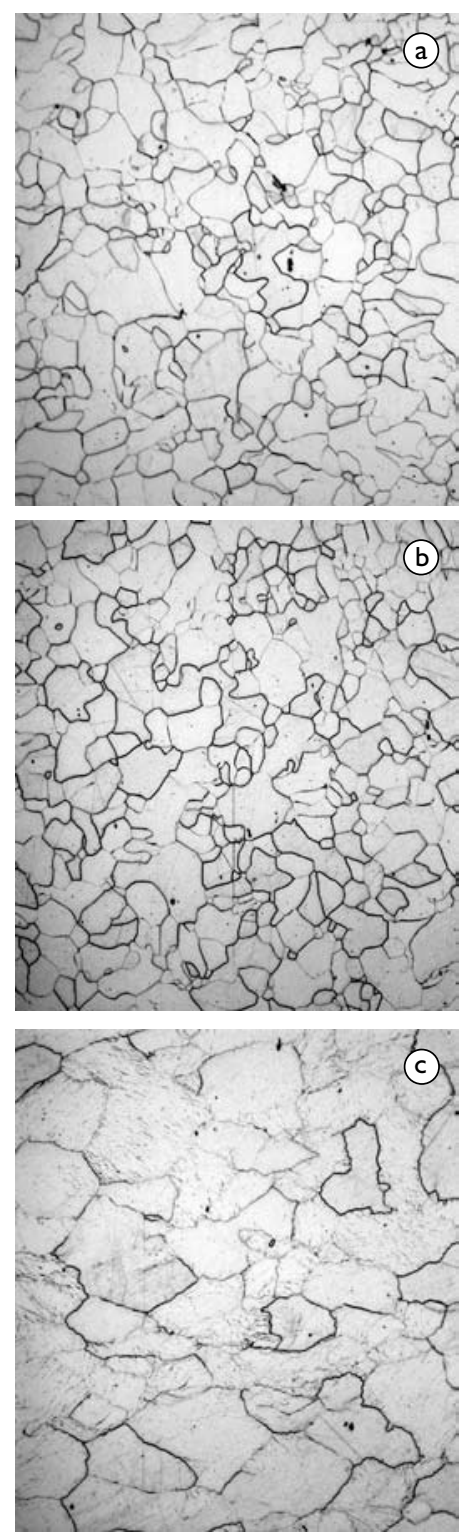

Figura 4. Microestrutura do aço após deformação em ensaio de compressão nas temperaturas de a) $1.000^{\circ} \mathrm{C}$; b) $950^{\circ} \mathrm{C}$; e c) $850^{\circ} \mathrm{C}$. Tempo de $0,5 \mathrm{~s}$ de encharque nestas temperaturas antes de resfriamento sob altas taxas. 
Como o aço avaliado neste estudo foi acabado industrialmente numa temperatura de aproximadamente $860^{\circ} \mathrm{C}$, pode-se dizer que sob estas condições tem-se, entre as cadeiras de laminação, uma efetiva condição de amaciamento estático. Como nas últimas cadeiras do trem de laminação o tempo entre passes situa-se entre $0,5 \mathrm{~s}$ e I s, e as taxas de deformação são superiores a $30 \mathrm{~s}^{-1}$, então, pode-se inferir que há um substancial amaciamento, podendo ser superior a $50 \%$.

As curvas de fração amaciada podem ser modeladas segundo equações do tipo Avrami, ${ }^{(6,10)}$ apesar do comportamento não totalmente sigmoidal na fase ferrítica $\left(850^{\circ} \mathrm{C}\right)$, da seguinte maneira:

$$
X=100\left\{1-\exp \left[-B\left(\frac{t}{t_{50}}\right)^{n}\right]\right\}
$$

em que $B$ e $n$ são constantes do aço.

Assim, o conhecimento de $t_{50}$ e $n$ permite uma completa descrição da cinética de recristalização.

Se na equação anterior for explicitado o valor de $\frac{100}{100-X}$ e tomado duas vezes o logarltmo natural deste parâmetro versus o logaritmo do tempo, para uma taxa de deformação de $\mathrm{I} \mathrm{s}^{-1}$ (como exemplo), conforme apresentado na Figura 5, têm-se curvas cujas inclinações correspondem ao expoente " $n$ " da equação anterior. Pode ser observado nesta figura que as inclinações das curvas nas temperaturas de $850^{\circ} \mathrm{C}, 950^{\circ} \mathrm{C}$ e $1.050^{\circ} \mathrm{C}$ são próximas. Isto significa que a "facilidade" de amaciamento nas três temperaturas é também próxima. Este resultado reforça as informações obtidas anteriormente das Figuras 2 e 3.

\section{CONCLUSÕES}

São verificadas características de restauração estática de um aço ultrabaixo carbono e com adições de silício e alumínio. Para isto empregou-se o ensaio mecânico de deformação a quente por compressão axissimétrica.

O aço é processado industrialmente com a laminação de acabamento ocorrendo inicialmente na fase austenítica, intermediariamente na fase intercrítica e, ao seu final, na região ferrítica.

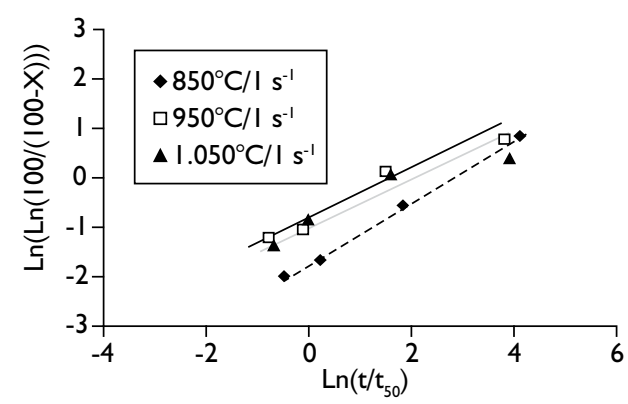

Figura 5. Variação do parâmetro $\operatorname{Ln}[100 /(100-X)]\}$ com a relação $t / t_{50}$.

As características de amaciamento entre passes $(\varepsilon=0,2)$ são investigadas pelo método da dupla deformação off set, sendo empregados três níveis de taxas de deformação $\left(1 \mathrm{~s}^{-1} ; 10 \mathrm{~s}^{-1}\right.$ e $\left.30 \mathrm{~s}^{-1}\right)$ e quatro tempos entre passes $(0,5 \mathrm{~s} ; 1,0 \mathrm{~s} ; 5,0 \mathrm{~s}$ e $50 \mathrm{~s}$ ). São avaliados três patamares de temperatura, ou seja: i) $850^{\circ} \mathrm{C}$ (fase ferrítica); ii) $950^{\circ} \mathrm{C}$ (fase intercrítica) e iii) $1.050^{\circ} \mathrm{C}$ (fase austenítica).

A fração amaciada cresceu com a taxa de deformação e o tempo entre passes.

Conclui-se também que, nas três temperaturas, a restauração foi rápida. Isto pode ser verificado pelo tempo necessário para ocorrer $50 \%$ de fração amaciada e pelo expoente $n$ de avanço logarítmico da fração de amaciamento.

Assim, infere-se que o aço avaliado possui boa capacidade de amaciamento entre passes durante sua laminação industrial.

Baseado no formato não essencialmente sigmoidal das curvas de amaciamento na temperatura de $850^{\circ} \mathrm{C}$ (fase ferrítica), e também em aspectos microestruturais, infere-se que nesta temperatura parece ter havido preponderantemente restauração via recristalização por SIBM e recuperação. Já nas fases intercríticas e austenítica, o modo de amaciamento deu-se por formação e crescimento de subgrãos. 


\section{REFERÊNCIAS}

I MARRA, K.M.; MELO, E.G.; RIBEIRO, C.F. Série USICORE - Aços elétricos semiprocessados. In: CONGRESSO ANUAL DA ABM, 54., 1999, São Paulo, SP. Anais... São Paulo: ABM, 1999. p.729-38.

2 MARRA, K.M.; MELO, E.G.; VIEIRA, C.F. Influência das condições de descarbonetação nas propriedades magnéticas do aço USICORE 260. In: CONGRESSO ANUAL DA ABM, 56, 200 I, Belo Horizonte, MG. Anais... São Paulo: ABM, 200I. p. 78-83.

3 KILBER, J.; SCHINDLER, I. Recrystalization/precipitation behaviour in microalloyed steels. Journal of Materials Processing and Technology, v. 60, n. I, p. 597-602, Jun. 1996.

4 SCHINDLER, I.; KILBER, J.; BORUTA, J. Mathematical description of static recovery of type C-Mn-Mo-Nb-V microalloyed steel. Steel Research, v. 6I, n. 6, p. 266-7I, Apr. 1991.

5 ANDRADE, H.L.; JONAS, J.J. Effect of molybdenum, niobium and vanadium on static recovery and recrystalization on solute strengthening in microalloyed steels. Metallurgical Transactions A, v. I4A, n. 10, p. 1967-77, Oct. 1983.

6 LAASRAOUI, A. Computer modelling of temperature, flow stress and microstructure during the hot rolling of steels. 1990. 290 p. (Thesis) - McGill University, Montreal, Canada, 1990.

7 PADILHA, A.F; SICILIANO JUNIOR, F. Encruamento, recristalização e textura. São Paulo: Associação Brasileira de Metalurgia e Materiais, 1996.

8 SANTOS, A.A. Análise crítica de equações para a cinética de recristalização estática durante a laminação a quente de aços CMn. In: CONGRESSO ANUAL DA ABM, 59., 2004, São Paulo, SP. Anais... São Paulo: ABM, 2004. p.3038-47.

9 HUMPPHREYS, F. J.; HATHERLY, M. Recrystallization and related annealing phenomena. Oxford: Elsevier Science, 1995.

I0 COLAS, R. Mathematical modelling of hot rolling steel strip. Materials Science and Technology, v. 14, n. 5, p. 388-93, May 1988.

Recebido em: II/12/07

Aceito em: 15/08/08

Proveniente de: CONGRESSO ANUAL DA ABM, 62., 2007, Vitória, ES. São Paulo: ABM, 2007. 